\title{
The split common fixed-point problem for demicontractive mappings and quasi-nonexpansive mappings
}

\author{
Yaqin Wang ${ }^{\mathrm{a}, *}$, Tae-Hwa Kim ${ }^{\mathrm{b}}$, Xiaoli Fang ${ }^{\mathrm{a}}$, Huimin $\mathrm{He}^{\mathrm{c}}$ \\ a Department of Mathematics, Shaoxing University, Shaoxing 312000, China. \\ ${ }^{b}$ Department of Applied Mathematics, College of Natural Sciences, Pukyong National University, Busan 48513, Korea. \\ 'School of Mathematics and Statistics, Xidian University, Xi'an 710071, China.
}

Communicated by P. Kumam

\begin{abstract}
In this paper, we study a split common fixed-point problem for demicontractive mappings and quasi-nonexpansive mappings, and propose some cyclic iterative schemes. Moreover we prove some strong convergence theorems. The results obtained in this paper generalize and improve the recent ones announced by many others. (C)2017 All rights reserved.
\end{abstract}

Keywords: Split common fixed-point problem, demicontractive mapping, strong convergence, cyclic iterative scheme. 2010 MSC: 47H05, 47H09, 47H20.

\section{Introduction}

Let $\mathrm{C}$ and $\mathrm{Q}$ be nonempty closed convex subsets of real Hilbert spaces $\mathrm{H}_{1}$ and $\mathrm{H}_{2}$, respectively, and let $A: H_{1} \rightarrow H_{2}$ be a bounded linear operator. The split feasibility problem (SFP) originally introduced in Censor and Elfving [1] is to find a point $x^{*} \in \mathrm{C}$ with the property:

$$
x^{*} \in C \text { and } A x^{*} \in Q .
$$

It serves as a model for many inverse problems where constraints are imposed on the solutions in the domain of a linear operator as well as in these operator's ranges. There are a number of significant applications of the SFP in intensity-modulated radiation therapy, signal processing, image reconstruction and so on. Recently the SFP has been widely studied by many authors (see, e.g., [3, 12, 13, 14]).

In the case where $C$ and $Q$ in the SFP (1.1) are the intersections of finitely many fixed-point sets of nonlinear operators, the problem (1.1) is called by Censor and Segal [2] the split common fixed-point problem (SCFP). More precisely, the SCFP requires to seek an element $x^{*} \in \mathrm{H}_{1}$ satisfying

$$
x^{*} \in \cap_{i=1}^{p} \operatorname{Fix}\left(\mathrm{U}_{i}\right) \text { and } A x^{*} \in \cap_{j=1}^{s} \operatorname{Fix}\left(\mathrm{T}_{j}\right),
$$

\footnotetext{
${ }^{*}$ Corresponding author

Email addresses: wangyaqin0579@126.com (Yaqin Wang), taehwa@pknu.ac .kr (Tae-Hwa Kim), fx10418@126.com (Xiaoli Fang), huiminhe@126. com (Huimin He)

doi:10.22436/jnsa.010.06.12
} 
where $p, s \geqslant 1$ are integers, Fix $\left(U_{i}\right)$ and $\operatorname{Fix}\left(T_{j}\right)$ denote the fixed point sets of two classes of nonlinear operators $U_{i}: H_{1} \rightarrow H_{1}(i=1,2, \cdots, p), T_{j}: H_{2} \rightarrow H_{2}(j=1,2, \cdots, s)$. In particular, if $p=s=1$, the problem (1.2) is reduced to find a point $x^{*}$ with the property:

$$
x^{*} \in \operatorname{Fix}(\mathrm{U}) \text { and } A x^{*} \in \operatorname{Fix}(T),
$$

which is usually called the two-set SCFP. To solve the two-set SCFP (1.3), Censor and Segal [2] proposed the following iterative method: for any initial guess $x_{1} \in H_{1}$, define $\left\{x_{n}\right\}$ recursively by

$$
x_{n+1}=U\left(x_{n}-\lambda A^{*}(I-T) A x_{n}\right),
$$

where $\mathrm{U}$ and $\mathrm{T}$ are directed operators. The further generalization of this algorithm was studied by Moudafi [8] for demicontractive operators. Under suitable conditions he proved that the sequence $\left\{x_{n}\right\}$ converges weakly to a point of the two-set SCFP (1.3).

Recently, Wang and $\mathrm{Xu}$ [10] proposed the following cyclic algorithm:

$$
x_{n+1}=U_{[n]}\left(x_{n}-\lambda A^{*}\left(I-T_{[n]}\right) A x_{n}\right),
$$

where $U_{i}$ and $T_{i}$ are directed operators for $i=1,2, \cdots, p,[n]=n(\bmod p)$. They proved that the sequence $\left\{x_{n}\right\}$ generated by this algorithm converges weakly to a solution of the problem (1.2) if $p=s$.

Since the existing algorithm for the SCFP (1.2) has only weak convergence in infinite-dimensional spaces (see [8, 10]), Cui et al. [3] proposed a new iterative scheme as follows:

$$
x_{n+1}=\left(1-\beta_{n}\right) x_{n}+\beta_{n} U_{[n]}\left[\left(1-\alpha_{n}\right)\left(x_{n}-\lambda_{n} A^{*}\left(I-T_{[n]}\right) A x_{n}\right)\right],
$$

where $U_{i}$ and $T_{i}$ are directed operators for $i=1,2, \cdots, p$. They proved that the sequence $\left\{x_{n}\right\}$ converges strongly to a solution of the problem (1.2) if $p=s$.

Motivated by the above works, we propose two algorithms for solving the SCFP (1.2) in the more general case of mappings which are demicontractive and quasi-nonexpansive, including nonexpansive mappings and directed operators in infinite-dimensional spaces and establish some strong convergence theorems.

\section{Preliminaries}

Throughout this paper, let $\mathrm{N}$ and $\mathrm{R}$ be the set of positive integers and real numbers, respectively. Let $H$ be a real Hilbert space with inner product $\langle\cdot, \cdot\rangle$, and norm $\|\cdot\|$. When $\left\{x_{n}\right\}$ is a sequence in $H$, we denote the strong convergence of $\left\{x_{n}\right\}$ to $x \in H$ by $x_{n} \rightarrow x$ and the weak convergence by $x_{n} \rightarrow x$. Let $T$ be a mapping of $\mathrm{C}$ into $\mathrm{H}$. We denote by Fix $(\mathrm{T})$ the set of fixed points of $\mathrm{T}$.

In order to facilitate our investigation in this paper, we recall some definitions as follows.

Definition 2.1. A mapping $T: H \rightarrow H$ is said to be

(i) nonexpansive if

$$
\|T x-T y\| \leqslant\|x-y\|, \quad \forall x, y \in H
$$

(ii) quasi-nonexpansive if

$$
\|\mathrm{T} x-\mathrm{q}\| \leqslant\|x-\mathrm{q}\|, \quad \forall(x, \mathrm{q}) \in \mathrm{H} \times \operatorname{Fix}(\mathrm{T}) ;
$$

(iii) firmly nonexpansive if

$$
\|T x-T y\|^{2} \leqslant\langle x-y, T x-T y\rangle, \quad \forall x, y \in H
$$

(iv) directed if

$$
\|\mathrm{T} x-\mathrm{q}\|^{2} \leqslant\|x-\mathrm{q}\|^{2}-\|x-\mathrm{T} x\|^{2}, \quad \forall(x, \mathrm{q}) \in \mathrm{H} \times \mathrm{Fix}(\mathrm{T}) ;
$$


(v) $\mu$-demicontractive if there exists a constant $\mu \in(-\infty, 1)$ such that

$$
\|\mathrm{T} x-\mathrm{q}\|^{2} \leqslant\|x-\mathrm{q}\|^{2}+\mu\|x-\mathrm{T} x\|^{2}, \quad \forall(x, \mathrm{q}) \in \mathrm{H} \times \mathrm{Fix}(\mathrm{T}),
$$

which is equivalent to

$$
\langle x-\mathrm{T} x, x-\mathrm{q}\rangle \geqslant \frac{1-\mu}{2}\|x-\mathrm{T} x\|^{2} .
$$

It is worth noting that the class of demicontractive mappings contains important mappings such as quasi-nonexpansive mappings and directed operators.

Remark 2.2. Notice that 0 -demicontractive is exactly quasi-nonexpansive. In particular, we say that it is quasi-strictly pseudo-contractive [7], if $0 \leqslant \mu<1$. Moreover, if $\mu \leqslant 0$, every $\mu$-demicontractive mapping becomes quasi-nonexpansive. So, it seems to be sufficient to only take $\mu \in(0,1)$ in $(v)$ of Definition 2.1 in Hilbert spaces. However, as seen in (iv) of Definition 2.1, every directed operator is obvious (-1)demicontractive.

Recall that the metric (or nearest point) projection from $\mathrm{H}$ onto $\mathrm{C}$ is the mapping $\mathrm{P}: \mathrm{H} \rightarrow \mathrm{C}$ which assigns to each point $x \in H$ the unique point $P_{C} x \in C$ satisfying the property

$$
\left\|x-P_{C} x\right\|=\inf _{y \in C}\|x-y\| .
$$

It is well-known that $P_{C} x$ is characterized by the inequality

$$
\left\langle x-P_{C} x, y-P_{C} x\right\rangle \leqslant 0, \quad \forall y \in C .
$$

Let us also recall that $I-T$ is said to be demiclosed at origin, if for any sequence $\left\{x_{k}\right\} \subset H$ and $x^{*} \in H$, we have

$$
\left.\begin{array}{l}
x_{k} \rightarrow x^{*} \\
(\mathrm{I}-\mathrm{T}) x_{\mathrm{k}} \rightarrow 0
\end{array}\right\} \Rightarrow x^{*}=\mathrm{T} x^{*}
$$

As a special case of the demicloseness principle on uniformly convex Banach spaces given by [4], we know that if $\mathrm{C}$ is a nonempty closed convex subset of a Hilbert space $\mathrm{H}$, and $\mathrm{T}: \mathrm{C} \rightarrow \mathrm{H}$ is a nonexpansive mapping. Then the mapping $\mathrm{I}-\mathrm{T}$ is demiclosed on $\mathrm{C}$. Now the following question is naturally raised: If $\mathrm{T}: \mathrm{C} \rightarrow \mathrm{H}$ is quasi-nonexpansive, is $\mathrm{I}-\mathrm{T}$ still demiclosed on $\mathrm{C}$ ? The answer is negative even at 0 as follows.

Example 2.3 (see [9, Example 2.11]). The mapping $\mathrm{T}:[0,1] \rightarrow[0,1]$ is defined by

$$
\mathrm{T} x= \begin{cases}\frac{x}{5}, & x \in\left[0, \frac{1}{2}\right] \\ x \sin \pi x, & x \in\left(\frac{1}{2}, 1\right] .\end{cases}
$$

Then $\mathrm{T}$ is a quasi-nonexpansive mapping, but $\mathrm{I}-\mathrm{T}$ is not demiclosed at 0.

Remark 2.4. Notice that a demicontractive mapping could enjoy the demiclosedness property at origin, for example, let $\mathrm{H}=\ell_{2}$ and let $\mathrm{T}: \mathrm{C} \rightarrow \mathrm{H}$ be defined by $\mathrm{T} x=-k x$, for arbitrary $x \in \ell_{2}$, where $\mathrm{k}>1$ (see [9, Example 2.5]). Then T is not quasi-nonexpansive but $\mu$-demicontactive, where $\mu=\frac{k-1}{k+1}$. However, $I-T$ is obviously demiclosed at 0 . For, whenever $\left\{x_{n}\right\}$ is any sequence in $\ell_{2}$ such that $x_{n} \rightarrow x \in \ell_{2}$ and $\left\|x_{n}-T x_{n}\right\| \rightarrow 0$, we readily see that $x=0 \in F(T)$.

In what follows, we give some lemmas needed for the convergence analysis of our algorithms. Let $\mathrm{H}_{1}$ and $\mathrm{H}_{2}$ be two real Hilbert spaces.

Lemma 2.5 ([11]). Assume that $\left\{a_{n}\right\}$ is a sequence of non-negative real numbers such that

$$
a_{n+1} \leqslant\left(1-\gamma_{n}\right) a_{n}+\gamma_{n} b_{n},
$$

where $\left\{\gamma_{n}\right\}$ is a sequence in $(0,1)$ and $\left\{b_{n}\right\}$ is a sequence in $R$ such that 
(i) $\sum_{n=1}^{\infty} \gamma_{n}=\infty$;

(ii) $\limsup _{n \rightarrow \infty} b_{n} \leqslant 0$ or $\sum_{n=1}^{\infty} \gamma_{n}\left|b_{n}\right|<\infty$.

Then $\lim _{n \rightarrow \infty} a_{n}=0$.

Lemma 2.6 ([10]). Assume that $\mathrm{A}: \mathrm{H}_{1} \rightarrow \mathrm{H}_{2}$ is a bounded linear operator and $\mathrm{T}: \mathrm{H}_{2} \rightarrow \mathrm{H}_{2}$ is a demicontractive operator. Let $\mathrm{V}_{\lambda}=\mathrm{I}-\lambda \mathrm{A}^{*}(\mathrm{I}-\mathrm{T}) \mathrm{A}$ with $\lambda>0$. Then

$$
\operatorname{Fix}\left(V_{\lambda}\right)=A^{-1}(\operatorname{Fix}(T)),
$$

whenever $\mathrm{A}^{-1}(\mathrm{Fix}(\mathrm{T}))=\left\{x \in \mathrm{H}_{1}: \mathrm{A} x \in \operatorname{Fix}(\mathrm{T})\right\}$.

Lemma 2.7 ([8]). Assume that $\mathrm{A}: \mathrm{H}_{1} \rightarrow \mathrm{H}_{2}$ is a bounded linear operator and $\mathrm{T}: \mathrm{H}_{2} \rightarrow \mathrm{H}_{2}$ is a $\mu$-demicontractive operator. Let $\mathrm{V}_{\lambda}=\mathrm{I}-\lambda \mathrm{A}^{*}(\mathrm{I}-\mathrm{T}) \mathrm{A}, \lambda \in(0,(1-\mu) / \rho)$ with $\rho$ being the spectral radius of the operator $\mathrm{A}^{*} \mathrm{~A}$. Then

(i)

$$
\left\|\mathrm{V}_{\lambda} x-z\right\|^{2} \leqslant\|x-z\|^{2}-\lambda(1-\mu-\rho \lambda)\|(\mathrm{I}-\mathrm{T}) A x\|^{2}, \quad \forall z \in A^{-1}(\operatorname{Fix}(\mathrm{T})),
$$

consequently,

(ii)

$$
\left\|\mathrm{V}_{\lambda} x-z\right\| \leqslant\|x-z\|, \quad \forall z \in \mathrm{A}^{-1}(\operatorname{Fix}(\mathrm{T})) .
$$

Lemma 2.8 ([5]). For any $x, y \in \mathrm{H}$ and $\lambda \in \mathrm{R}$, the following hold:

(a) $\|\lambda x+(1-\lambda) y\|^{2}=\lambda\|x\|^{2}+(1-\lambda)\|y\|^{2}-\lambda(1-\lambda)\|x-y\|^{2} ;$

(b) $\|x+y\|^{2} \leqslant\|x\|^{2}+2\langle y, x+y\rangle$.

Lemma 2.9 ([7, Proposition 2.1]). Assume $\mathrm{C}$ is a closed convex subset of a Hilbert space $\mathrm{H}$. Let $\mathrm{T}: \mathrm{C} \rightarrow \mathrm{C}$ be a self-mapping of $\mathrm{C}$. If $\mathrm{T}$ is a $\mu$-demicontractive mapping (which is also called $\mu$-quasi-strict pseudo-contraction in [7]), then the fixed point set $\mathrm{F}(\mathrm{T})$ is closed and convex.

\section{Main results}

In this section, let $\mathrm{H}_{1}$ and $\mathrm{H}_{2}$ be two real Hilbert spaces. We consider the SCFP (1.2) with $p=s$ to find an element $x^{*} \in \mathrm{H}_{1}$ satisfying

$$
x^{*} \in \cap_{i=1}^{p} \operatorname{Fix}\left(U_{i}\right) \text { and } A x^{*} \in \cap_{i=1}^{p} \operatorname{Fix}\left(T_{i}\right),
$$

where $p$ is a positive integer. Denote the solution set of the SCFP (3.1) by $\Omega$, i.e.,

$$
\Omega=\left(\cap_{i=1}^{p} \operatorname{Fix}\left(U_{i}\right)\right) \bigcap A^{-1}\left(\cap_{i=1}^{p} \operatorname{Fix}\left(T_{i}\right)\right) .
$$

Note that the problem (3.1) is a special case of the problem (1.2). However, this is not restrictive. Because following an idea in [10], one can easily extend the results to the general case.

For fixed positive integer $p$ and each $n \geqslant 1$, the $p$-mod function $[n]$ is defined by

$$
[n]= \begin{cases}p, & \text { if } r=0, \\ r, & \text { if } 0<r<p,\end{cases}
$$

whenever $n=k p+r$ for some $k \geqslant 0$.

Lemma 3.1. Let $\left\{\mathfrak{u}_{\mathrm{k}}\right\}$ be a bounded sequence of a Hilbert space $\mathrm{H}$. Let $\mathrm{p}$ be a positive integer and $\mathrm{I}=\{1,2, \cdots, \mathrm{p}\}$. If $\lim _{k \rightarrow \infty}\left\|\mathfrak{u}_{k+1}-\mathfrak{u}_{k}\right\|=0$ and $x^{*} \in \omega_{w}\left(\mathfrak{u}_{k}\right)$, then for any $i \in I$, there exists a subsequence $\left\{\mathfrak{u}_{k_{m}}\right\}$ of $\left\{\mathfrak{u}_{k}\right\}$ such that $\left[k_{\mathrm{m}}\right]=i$ and $u_{k_{\mathrm{m}}} \rightarrow x^{*}$. 
Proof. Obviously, $\omega_{w}\left(\mathfrak{u}_{k}\right) \neq \emptyset$ from boundedness of $\left\{\mathfrak{u}_{k}\right\}$. Now for any $i \in I$, since $\lim _{k \rightarrow \infty}\left\|\mathfrak{u}_{k+1}-\mathfrak{u}_{k}\right\|=$ 0 , we have

$$
\left\|\mathfrak{u}_{k+i}-\mathfrak{u}_{k}\right\| \leqslant\left\|u_{k+i}-u_{k+i-1}\right\|+\left\|u_{k+i-1}-u_{k+i-2}\right\|+\cdots+\left\|u_{k+1}-u_{k}\right\| \rightarrow 0 .
$$

It follows from $x^{*} \in \omega_{w}\left(u_{k}\right)$ that there exists a subsequence $\left\{u_{t_{m}}\right\}$ of $\left\{u_{k}\right\}$ such that $u_{t_{m}} \rightarrow x^{*}$. So due to $\left\|u_{k+i}-u_{k}\right\| \rightarrow 0$ we obtain $u_{t_{m}+i} \rightarrow x^{*}$ for all $i \in I$. For any $i \in I$, there exists $t_{1}+i_{1} \in$ $\left\{t_{1}+1, t_{1}+2, \cdots, t_{1}+p\right\}$ such that $\left[t_{1}+i_{1}\right]=i$. We choose $k_{1}=t_{1}+i_{1}$. And there exists $t_{2}+i_{2} \in$ $\left\{t_{2}+1, t_{2}+2, \cdots, t_{2}+p\right\}$ such that $\left[t_{2}+i_{2}\right]=i$. If $t_{2}+i_{2}>k_{1}$, we choose $k_{2}=t_{2}+i_{2} ;$ if $t_{2}+i_{2} \leqslant k_{1}$, we skip it and go to the $t_{3}$. Repeating this process continuously, we can choose a subsequence $\left\{k_{m}\right\}$ such that $\left[k_{m}\right]=i$ for all $m \geqslant 1$ and $u_{k_{m}} \rightarrow x^{*}$ too.

Theorem 3.2. Let $\mathrm{U}_{i}$ be quasi-nonexpansive and $\mathrm{T}_{i}$ be $\mu_{i}$-demicontractive such that $\mathrm{I}-\mathrm{U}_{i}$ and $\mathrm{I}-\mathrm{T}_{i}$ are demiclosed at origin for every $i=1,2, \cdots, p$. Let $\mathrm{A}: \mathrm{H}_{1} \rightarrow \mathrm{H}_{2}$ be a bounded linear operator. Assume that $\Omega \neq \emptyset$ and $\rho$ is as in Lemma 2.7. For any $x_{1} \in \mathrm{H}_{1}$, define the sequence $\left\{x_{n}\right\}$ by

$$
x_{n+1}=\left(1-\beta_{n}\right) x_{n}+\beta_{n} U_{n}\left[\left(1-\alpha_{n}\right)\left(x_{n}-\lambda_{n} A^{*}\left(I-T_{n}\right) A x_{n}\right)\right],
$$

where $\mathrm{U}_{\mathrm{n}}=\mathrm{U}_{[\mathrm{n}]}, \mathrm{T}_{\mathrm{n}}=\mathrm{T}_{[\mathrm{n}]}$ and $\left\{\alpha_{n}\right\} \subset(0,1),\left\{\beta_{n}\right\} \subset[0,1],\left\{\lambda_{n}\right\} \subset[0,+\infty)$ satisfying the following conditions:

(i) $0<\liminf _{n \rightarrow \infty} \beta_{n} \leqslant \limsup _{n \rightarrow \infty} \beta_{n}<1$;

(ii) $\lim _{n \rightarrow \infty} \alpha_{n}=0, \sum_{n=1}^{\infty} \alpha_{n}=\infty$;

(iii) $0<\liminf _{n \rightarrow \infty} \lambda_{n} \leqslant \limsup _{n \rightarrow \infty} \lambda_{n}<\frac{1-\mu}{\rho}, \mu=\max _{1 \leqslant i \leqslant p}\left\{\mu_{i}\right\}$.

Then the sequence $\left\{x_{n}\right\}$ converges strongly to $\mathrm{P}_{\Omega}(0)$.

Proof. From Lemma 2.9, for every $i \in\{1,2, \cdots, p\}$, we notice that $F i x\left(T_{i}\right)$ and $F i x\left(U_{i}\right)$ are closed and convex. Thus $\bigcap_{i=1}^{p}$ Fix $\left(T_{i}\right)$ and $\bigcap_{i=1}^{p} F\left(U_{i}\right)$ are also closed and convex. Since $A$ is bounded and linear, $A^{-1}\left(\cap_{i=1}^{p}\right.$ Fix $\left.\left(T_{i}\right)\right)$ is closed and convex. Therefore, $\Omega$ is closed and convex.

Let $W_{n}=I-\lambda_{n} A^{*}\left(I-T_{n}\right) A, y_{n}=\left(1-\alpha_{n}\right) W_{n} x_{n}$. Let $z=P_{\Omega}(0)$. Noting that for every $i(1 \leqslant i \leqslant$ p), $\mu_{i} \leqslant \mu$, so from Lemma 2.7 and the condition (iii) we have

$$
\begin{aligned}
\left\|W_{n} x_{n}-z\right\|^{2} & \leqslant\left\|x_{n}-z\right\|^{2}-\lambda_{n}\left(1-\mu-\lambda_{n} \rho\right)\left\|\left(I-T_{n}\right) A x_{n}\right\|^{2} \\
& \leqslant\left\|x_{n}-z\right\|^{2} .
\end{aligned}
$$

It follows from (3.4) that

$$
\begin{aligned}
\left\|y_{n}-z\right\| & =\left\|\left(1-\alpha_{n}\right)\left(W_{n} x_{n}-z\right)-\alpha_{n} z\right\| \\
& \leqslant\left(1-\alpha_{n}\right)\left\|W_{n} x_{n}-z\right\|+\alpha_{n}\|z\| \\
& \leqslant\left(1-\alpha_{n}\right)\left\|x_{n}-z\right\|+\alpha_{n}\|z\|,
\end{aligned}
$$

then

$$
\begin{aligned}
\left\|x_{n+1}-z\right\| & \leqslant\left(1-\beta_{n}\right)\left\|x_{n}-z\right\|+\beta_{n}\left\|u_{n} y_{n}-z\right\| \\
& \leqslant\left(1-\beta_{n}\right)\left\|x_{n}-z\right\|+\beta_{n}\left\|y_{n}-z\right\| \\
& \leqslant\left(1-\beta_{n}\right)\left\|x_{n}-z\right\|+\beta_{n}\left[\left(1-\alpha_{n}\right)\left\|x_{n}-z\right\|+\alpha_{n}\|z\|\right] \\
& =\left(1-\alpha_{n} \beta_{n}\right)\left\|x_{n}-z\right\|+\alpha_{n} \beta_{n}\|z\| \\
& \leqslant \max \left\{\left\|x_{1}-z\right\|,\|z\|\right\} .
\end{aligned}
$$


Thus $\left\{x_{n}\right\}$ is bounded and so are $\left\{y_{n}\right\}$ and $\left\{W_{n} x_{n}\right\}$. From (3.3), the quasi-nonexpansivity of $U_{n}$ and Lemma $2.8(b)$, we obtain

$$
\begin{aligned}
\left\|\mathrm{u}_{n} y_{n}-z\right\|^{2} \leqslant & \left\|y_{n}-z\right\|^{2} \\
= & \left\|\left(1-\alpha_{n}\right)\left(W_{n} x_{n}-z\right)-\alpha_{n} z\right\|^{2} \\
\leqslant & \left(1-\alpha_{n}\right)\left\|W_{n} x_{n}-z\right\|^{2}+2 \alpha_{n}\left\langle z, z-y_{n}\right\rangle \\
\leqslant & \left(1-\alpha_{n}\right)\left\|x_{n}-z\right\|^{2}+2 \alpha_{n}\left\langle z, z-y_{n}\right\rangle \\
& -\lambda_{n}\left(1-\alpha_{n}\right)\left(1-\mu-\lambda_{n} \rho\right)\left\|\left(I-T_{n}\right) A x_{n}\right\|^{2} .
\end{aligned}
$$

It follows from (3.2), (3.5) and Lemma 2.8 (a) that

$$
\begin{aligned}
\left\|x_{n+1}-z\right\|^{2}= & \left\|\left(1-\beta_{n}\right)\left(x_{n}-z\right)+\beta_{n}\left(U_{n} y_{n}-z\right)\right\|^{2} \\
= & \left.\left(1-\beta_{n}\right)\left\|x_{n}-z\right\|^{2}+\beta_{n} \| U_{n} y_{n}-z\right)\left\|^{2}-\beta_{n}\left(1-\beta_{n}\right)\right\| U_{n} y_{n}-x_{n} \|^{2} \\
\leqslant & \left(1-\beta_{n}\right)\left\|x_{n}-z\right\|^{2}-\beta_{n}\left(1-\beta_{n}\right)\left\|U_{n} y_{n}-x_{n}\right\|^{2} \\
& +\beta_{n}\left[\left(1-\alpha_{n}\right)\left\|x_{n}-z\right\|^{2}+2 \alpha_{n}\left\langle z, z-y_{n}\right\rangle\right. \\
& \left.-\lambda_{n}\left(1-\alpha_{n}\right)\left(1-\mu-\lambda_{n} \rho\right)\left\|\left(I-T_{n}\right) A x_{n}\right\|^{2}\right] \\
= & \left(1-\alpha_{n} \beta_{n}\right)\left\|x_{n}-z\right\|^{2}+2 \alpha_{n} \beta_{n}\left\langle z, z-y_{n}\right\rangle \\
& -\beta_{n}\left(1-\beta_{n}\right)\left\|U_{n} y_{n}-x_{n}\right\|^{2}-\lambda_{n} \beta_{n}\left(1-\alpha_{n}\right)\left(1-\mu-\lambda_{n} \rho\right)\left\|\left(I-T_{n}\right) A x_{n}\right\|^{2},
\end{aligned}
$$

i.e., we have the following inequality

$$
\begin{aligned}
s_{n+1} & \leqslant\left(1-\alpha_{n} \beta_{n}\right) s_{n}+2 \alpha_{n} \beta_{n}\left\langle z, z-y_{n}\right\rangle-c_{n} \\
& \leqslant\left(1-\alpha_{n} \beta_{n}\right) s_{n}+2 \alpha_{n} \beta_{n}\left\langle z, z-y_{n}\right\rangle,
\end{aligned}
$$

where $s_{n}=\left\|x_{n}-z\right\|^{2}$ and

$$
c_{n}=\lambda_{n} \beta_{n}\left(1-\alpha_{n}\right)\left(1-\mu-\lambda_{n} \rho\right)\left\|\left(I-T_{n}\right) A x_{n}\right\|^{2}+\beta_{n}\left(1-\beta_{n}\right)\left\|U_{n} y_{n}-x_{n}\right\|^{2} .
$$

It follows from (3.6) that

$$
c_{n} \leqslant M \alpha_{n} \beta_{n}+s_{n}-s_{n+1}
$$

where $M=2 \sup _{n \geqslant 1}\left\{\|z\| \cdot\left\|z-y_{n}\right\|\right\}$.

Finally we will prove $s_{n} \rightarrow 0$. To see this, let us consider two possible cases on such a sequence and employ an idea developed by Mainge [6].

Case I. Assume that there exists an integer $N_{1}$ such that $s_{n} \geqslant s_{n+1}$ for all $n \geqslant N_{1}$. In this case $\left\{s_{n}\right\}$ must be convergent. So due to (3.8) and the conditions (i)-(iii), we have both $\left\{\left\|\left(I-T_{n}\right) A x_{n}\right\|\right\}$ and $\left\{\left\|U_{n} y_{n}-x_{n}\right\|\right\}$ converge to zero. Then we obtain

$$
\left\|x_{n+1}-x_{n}\right\|=\beta_{n}\left\|u_{n} y_{n}-x_{n}\right\| \rightarrow 0,
$$

and

$$
\begin{aligned}
\left\|y_{n}-x_{n}\right\| & =\left\|\left(1-\alpha_{n}\right)\left(x_{n}-\lambda_{n} A^{*}\left(I-T_{n}\right) A x_{n}\right)-x_{n}\right\| \\
& =\left\|\left(1-\alpha_{n}\right) \lambda_{n} A^{*}\left(I-T_{n}\right) A x_{n}+\alpha_{n} x_{n}\right\| \\
& \leqslant\left(1-\alpha_{n}\right) \lambda_{n}\left\|A^{*}\right\| \cdot\left\|\left(I-T_{n}\right) A x_{n}\right\|+\alpha_{n}\left\|x_{n}\right\| \rightarrow 0 .
\end{aligned}
$$

Therefore

$$
\begin{aligned}
\left\|u_{n} y_{n}-y_{n}\right\| & \leqslant\left\|u_{n} y_{n}-x_{n}\right\|+\left\|x_{n}-y_{n}\right\| \rightarrow 0 \\
\left\|y_{n+1}-y_{n}\right\| & \leqslant\left\|y_{n+1}-x_{n+1}\right\|+\left\|x_{n+1}-x_{n}\right\|+\left\|x_{n}-y_{n}\right\| \rightarrow 0
\end{aligned}
$$


Take a subsequence $\left\{y_{n_{k}}\right\}$ of $\left\{y_{n}\right\}$ such that

$$
\limsup _{n \rightarrow \infty}\left\langle z, z-y_{n}\right\rangle=\lim _{k \rightarrow \infty}\left\langle z, z-y_{n_{k}}\right\rangle .
$$

Without loss of generality, we assume that $\left\{y_{n_{k}}\right\}$ converges weakly to an element $y^{*}$, then by (3.10) we have $y^{*} \in \omega_{w}\left(x_{n}\right)$. Let an index $i \in\{1,2, \cdots, p\}$ be fixed. Noting that the pool of indices is finite and (3.9), by Lemma 3.1 we can find a subsequence $\left\{x_{m_{k}}\right\} \subset\left\{x_{n}\right\}$ such that $x_{m_{k}} \rightarrow y^{*}$ and $\left[m_{k}\right]=i$ for all $k \geqslant 1$. So from (3.10) we obtain $y_{m_{k}} \rightarrow y^{*}$. Since

$$
\left\|\mathrm{u}_{\mathrm{i}} \mathrm{y}_{\mathrm{m}_{\mathrm{k}}}-\mathrm{y}_{\mathrm{m}_{\mathrm{k}}}\right\|=\left\|\mathrm{u}_{\mathrm{m}_{\mathrm{k}}} \mathrm{y}_{\mathrm{m}_{\mathrm{k}}}-\mathrm{y}_{\mathrm{m}_{\mathrm{k}}}\right\| \rightarrow 0,
$$

and $U_{i}-I$ is demiclosed at origin, we obtain $y^{*} \in \operatorname{Fix}\left(U_{i}\right)$. It follows from (3.10) and the weak continuity of $A$ that $A x_{m_{k}} \rightarrow A y^{*}$. Furthermore, since $I-T_{i}$ is demiclosed at origin and $\left\|\left(I-T_{i}\right) A x_{m_{k}}\right\| \rightarrow 0$, we have $A y^{*} \in \operatorname{Fix}\left(T_{i}\right)$. Since the index $i$ is arbitrary, we have $y^{*} \in \Omega$. Thus by (2.1) and $z=P_{\Omega}(0)$, we obtain

$$
\limsup _{n \rightarrow \infty}\left\langle z, z-y_{n}\right\rangle=\left\langle z, z-y^{*}\right\rangle \leqslant 0 .
$$

Now since all the hypotheses of Lemma 2.5 are fulfilled, we conclude that $s_{n} \rightarrow 0$.

Case II. Assume that there exists a subsequence $\left\{s_{m_{k}}\right\}$ of $\left\{s_{n}\right\}$ such that $s_{m_{k}}<s_{m_{k}+1}$ for all $k \geqslant 1$. Employing [6, Lemma 3.1] in Maingé, we can take a nondecreasing sequence $\{\tau(n)\}_{n} \geqslant n_{1}$ of integers satisfying the following properties:

$$
s_{\tau(n)} \leqslant s_{\tau(n)+1} \text { and } s_{n} \leqslant s_{\tau(n)+1}
$$

for all $n \geqslant n_{1}$. Then from (3.8) and $\alpha_{n} \rightarrow 0$ we have

$$
c_{\tau(n)} \leqslant s_{\tau(n)}-s_{\tau(n)+1}+\alpha_{\tau(n)} \beta_{\tau(n)} M \leqslant \alpha_{\tau(n)} \beta_{\tau(n)} M \rightarrow 0 .
$$

So it follows from the conditions (i)-(iii) that both $\left\{\left\|\left(I-T_{\tau(n)}\right) A x_{\tau(n)}\right\|\right\}$ and $\left\{\left\|U_{\tau(n)} y_{\tau(n)}-x_{\tau(n)}\right\|\right\}$ converge to zero. Being similar to the proof of (3.9) and (3.11) in Case I, we have

$$
\begin{aligned}
& \lim _{n \rightarrow \infty}\left\|x_{\tau(n)}-x_{\tau(n)+1}\right\|=0, \\
& \limsup _{n \rightarrow \infty}\left\langle z, z-y_{\tau(n)}\right\rangle \leqslant 0 .
\end{aligned}
$$

From (3.7) and $s_{\tau(n)} \leqslant s_{\tau(n)+1}$, we have

$$
s_{\tau(n)} \leqslant 2\left\langle z, z-y_{\tau(n)}\right\rangle .
$$

Hence from (3.12) we have $\lim \sup _{n \rightarrow \infty} s_{\tau(n)} \leqslant 0$, which implies that $s_{\tau(n)} \rightarrow 0$. Furthermore,

$$
\begin{aligned}
s_{\tau(n)+1} & \leqslant\left|s_{\tau(n)+1}-s_{\tau(n)}\right|+s_{\tau(n)} \\
& \leqslant\left\|x_{\tau(n)+1}-x_{\tau(n)}\right\|\left(\left\|x_{\tau(n)+1}-z\right\|+\left\|x_{\tau(n)}-z\right\|\right)+s_{\tau(n)} \rightarrow 0 .
\end{aligned}
$$

Therefore, it follows from $s_{\mathfrak{n}} \leqslant s_{\tau(n)+1}$ that $s_{n} \rightarrow 0$.

Remark 3.3. Compared with [3, Theorem 1], Theorem 3.2 relaxes the conditions on $\left\{T_{i}\right\}$ from directed mappings to demicontractive mappings and $\left\{\mathrm{U}_{\mathrm{n}}\right\}$ from directed mappings to quasi-nonexpansive mappings.

Theorem 3.4. Let $\mathrm{U}_{i}$ be quasi-nonexpansive and $\mathrm{T}_{i}$ be $\mu_{i}$-demicontractive such that $\mathrm{I}-\mathrm{U}_{i}$ and $\mathrm{I}-\mathrm{T}_{i}$ are demiclosed at origin for every $i=1,2, \cdots, p$. Let $A: H_{1} \rightarrow H_{2}$ be a bounded linear operator. Assume that $\Omega \neq \emptyset$ and $\rho$ is as in Lemma 2.7. For any $x_{1} \in \mathrm{H}_{1}$, define the sequence $\left\{x_{\mathrm{n}}\right\}$ by

$$
x_{n+1}=\left(1-\beta_{n}\right) W_{n} x_{n}+\beta_{n} u_{n}\left[\left(1-\alpha_{n}\right) W_{n} x_{n}\right],
$$

where $\mathrm{U}_{n}=\mathrm{U}_{[n]}, \mathrm{T}_{\mathrm{n}}=\mathrm{T}_{[\mathrm{n}]}, \mathrm{W}_{n} \mathrm{x}_{\mathrm{n}}=\mathrm{x}_{\mathrm{n}}-\lambda_{n} A^{*}\left(\mathrm{I}-\mathrm{T}_{\mathrm{n}}\right) A x_{n}$ and $\left\{\alpha_{n}\right\} \subset(0,1),\left\{\beta_{n}\right\} \subset[0,1],\left\{\lambda_{n}\right\} \subset$ $[0,+\infty)$ satisfying the following conditions: 
(i) $0<\liminf _{n \rightarrow \infty} \beta_{n} \leqslant \limsup _{n \rightarrow \infty} \beta_{n}<1$;

(ii) $\lim _{n \rightarrow \infty} \alpha_{n}=0, \sum_{n=1}^{\infty} \alpha_{n}=\infty$;

(iii) $0<\liminf _{n \rightarrow \infty} \lambda_{n} \leqslant \lim \sup _{n \rightarrow \infty} \lambda_{n}<\frac{1-\mu}{\rho}, \mu=\max _{1 \leqslant i \leqslant p}\left\{\mu_{i}\right\}$.

Then the sequence $\left\{x_{n}\right\}$ converges strongly to $P_{\Omega}(0)$.

Proof. Let $y_{n}=\left(1-\alpha_{n}\right) W_{n} x_{n}$ and $z=P_{\Omega}(0)$. It follows from (3.4) and (3.13) that

$$
\begin{aligned}
\left\|x_{n+1}-z\right\| & \leqslant\left(1-\beta_{n}\right)\left\|W_{n} x_{n}-z\right\|+\beta_{n}\left\|U_{n}\left[\left(1-\alpha_{n}\right) W_{n} x_{n}\right]-z\right\| \\
& \leqslant\left(1-\beta_{n}\right)\left\|W_{n} x_{n}-z\right\|+\beta_{n}\left\|\left(1-\alpha_{n}\right) W_{n} x_{n}-z\right\| \\
& \leqslant\left(1-\beta_{n}\right)\left\|W_{n} x_{n}-z\right\|+\beta_{n}\left(1-\alpha_{n}\right)\left\|W_{n} x_{n}-z\right\|+\alpha_{n} \beta_{n}\|z\| \\
& \leqslant\left(1-\alpha_{n} \beta_{n}\right)\left\|x_{n}-z\right\|+\alpha_{n} \beta_{n}\|z\| \\
& \leqslant \max \left\{\left\|x_{1}-z\right\|,\|z\|\right\},
\end{aligned}
$$

which implies that $\left\{x_{n}\right\}$ is bounded, further, $\left\{W_{n} x_{n}\right\}$ is bounded too. Since

$$
\begin{aligned}
\left\|y_{n}-z\right\| & \leqslant\left(1-\alpha_{n}\right)\left\|W_{n} x_{n}-z\right\|+\alpha_{n}\|z\| \\
& \leqslant\left(1-\alpha_{n}\right)\left\|x_{n}-z\right\|+\alpha_{n}\|z\|,
\end{aligned}
$$

$\left\{y_{n}\right\}$ is also bounded. It follows from (3.4), (3.5), (3.13) and Lemma 2.8 (a) that

$$
\begin{aligned}
\left\|x_{n+1}-z\right\|^{2}= & \left\|\left(1-\beta_{n}\right)\left(W_{n} x_{n}-z\right)+\beta_{n}\left(\mathrm{U}_{n} y_{n}-z\right)\right\|^{2} \\
= & \left.\left(1-\beta_{n}\right)\left\|W_{n} x_{n}-z\right\|^{2}+\beta_{n} \| \mathrm{U}_{n} y_{n}-z\right)\left\|^{2}-\beta_{n}\left(1-\beta_{n}\right)\right\| \mathrm{U}_{n} y_{n}-W_{n} x_{n} \|^{2} \\
\leqslant & \left(1-\beta_{n}\right)\left\|x_{n}-z\right\|^{2}+\beta_{n}\left[\left(1-\alpha_{n}\right)\left\|x_{n}-z\right\|^{2}+2 \alpha_{n}\left\langle z, z-y_{n}\right\rangle\right. \\
& \left.-\lambda_{n}\left(1-\alpha_{n}\right)\left(1-\mu-\lambda_{n} \rho\right)\left\|\left(I-T_{n}\right) A x_{n}\right\|^{2}\right]-\beta_{n}\left(1-\beta_{n}\right)\left\|U_{n} y_{n}-W_{n} x_{n}\right\|^{2} \\
= & \left(1-\alpha_{n} \beta_{n}\right)\left\|x_{n}-z\right\|^{2}+2 \alpha_{n} \beta_{n}\left\langle z, z-y_{n}\right\rangle-\beta_{n}\left(1-\beta_{n}\right)\left\|U_{n} y_{n}-W_{n} x_{n}\right\|^{2} \\
& -\beta_{n}\left(1-\alpha_{n}\right) \lambda_{n}\left(1-\mu-\lambda_{n} \rho\right)\left\|\left(I-T_{n}\right) A x_{n}\right\|^{2},
\end{aligned}
$$

i.e.,

$$
s_{n+1} \leqslant\left(1-\alpha_{n} \beta_{n}\right) s_{n}+2 \alpha_{n} \beta_{n}\left\langle z, z-y_{n}\right\rangle-c_{n}
$$

where

$$
c_{n}=\beta_{n}\left(1-\beta_{n}\right)\left\|U_{n} y_{n}-W_{n} x_{n}\right\|^{2}+\beta_{n}\left(1-\alpha_{n}\right) \lambda_{n}\left(1-\mu-\lambda_{n} \rho\right)\left\|\left(I-T_{n}\right) A x_{n}\right\|^{2},
$$

and $s_{n}=\left\|x_{n}-z\right\|^{2}$. First, in a similar way to the proof of Case I in Theorem 3.2, we have both $\{\|(I-$ $\left.\left.\mathrm{T}_{\mathrm{n}}\right) A \mathrm{x}_{\mathrm{n}} \|\right\}$ and $\left\{\left\|\mathrm{U}_{\mathrm{n}} \mathrm{y}_{\mathrm{n}}-\mathrm{W}_{\mathrm{n}} \mathrm{x}_{\mathrm{n}}\right\|\right\}$ converge to zero. Since

$$
\left\|W_{n} x_{n}-x_{n}\right\| \leqslant \lambda_{n}\left\|A^{*}\right\| \cdot\left\|\left(I-T_{n}\right) A x_{n}\right\| \rightarrow 0,
$$

we have

$$
\begin{aligned}
\left\|u_{n} y_{n}-x_{n}\right\| & \leqslant\left\|u_{n} y_{n}-W_{n} x_{n}\right\|+\left\|W_{n} x_{n}-x_{n}\right\| \rightarrow 0 \\
\left\|y_{n}-x_{n}\right\| & \leqslant\left\|\left(1-\alpha_{n}\right) W_{n} x_{n}-x_{n}\right\| \\
& \leqslant\left\|W_{n} x_{n}-x_{n}\right\|+\alpha_{n}\left\|W_{n} x_{n}\right\| \rightarrow 0
\end{aligned}
$$

It follows from (3.13), (3.15) and (3.16) that

$$
\left\|x_{n+1}-x_{n}\right\| \leqslant\left(1-\beta_{n}\right)\left\|W_{n} x_{n}-x_{n}\right\|+\beta_{n}\left\|U_{n} y_{n}-x_{n}\right\| \rightarrow 0 .
$$


From (3.16), (3.17), (3.18) we have

$$
\begin{aligned}
\left\|u_{n} y_{n}-y_{n}\right\| & \leqslant\left\|u_{n} y_{n}-x_{n}\right\|+\left\|x_{n}-y_{n}\right\| \rightarrow 0, \\
\left\|y_{n+1}-y_{n}\right\| & \leqslant\left\|y_{n+1}-x_{n+1}\right\|+\left\|x_{n+1}-x_{n}\right\|+\left\|x_{n}-y_{n}\right\| \rightarrow 0 .
\end{aligned}
$$

By virtue of (3.14), (3.18), (3.19), (3.20), and $\left\|\left(I-T_{n}\right) A x_{n}\right\| \rightarrow 0$, mimicking the proof of Case I and Case II in Theorem 3.2, we conclude that the sequence $\left\{x_{n}\right\}$ defined by (3.13) converges strongly to $z=\mathrm{P}_{\Omega}(0)$.

Now we shall give an example which satisfies all the conditions of the solution set $\Omega$ of the SCFP (3.1), the mappings $\left\{U_{i}\right\}_{i=1}^{p}$, and $\left\{T_{i}\right\}_{i=1}^{p}$ in Theorems 3.2 and 3.4.

Example 3.5. Let $\mathrm{H}_{1}=\mathrm{H}_{2}=\mathrm{H}_{3}=\ell_{2}$. For each $\mathrm{i} \in\{1,2, \cdots, \mathrm{p}\}$, let $\mathrm{U}_{i}, \mathrm{~T}_{\mathrm{i}}: \ell_{2} \rightarrow \ell_{2}$ be defined by

$$
u_{i} x=(\overbrace{0, \cdots, 0}^{i}, x_{1}, x_{2}, \cdots),
$$

and $\mathrm{T}_{\mathrm{i}} \mathrm{x}=-(\mathrm{i}+1) \mathrm{x}$ for all $\mathrm{x}=\left(\mathrm{x}_{1}, \mathrm{x}_{2}, \cdots\right) \in \ell_{2}$. Then

$$
\Omega=\left(\cap_{i=1}^{p} \operatorname{Fix}\left(U_{i}\right)\right) \bigcap A^{-1}\left(\cap_{i=1}^{p} \operatorname{Fix}\left(T_{i}\right)\right)=\{0\} .
$$

Furthermore, for each $i \in\{1,2, \cdots, p\}, \mathrm{U}_{i}$ is quasi-nonexpansive, $\mathrm{T}_{i}$ is $\mu$-demicontractive with $\mu=\frac{i}{i+2}, \mathrm{I}-\mathrm{U}_{i}$ and $\mathrm{I}-\mathrm{T}_{i}$ are demiclosed at 0 .

In fact, since $\cap_{i=1}^{p} \operatorname{Fix}\left(U_{i}\right)=\{0\}=\cap_{i=1}^{p} F i x\left(T_{i}\right)$, it results that $\Omega=\{0\}$. Now we show the demicloseness property of $I-U_{i}$ at $0(i=1,2, \cdots p)$. To this end, for any $i \in\{1,2, \cdots p\}$, let $x_{n} \rightarrow z$ and $\left(I-U_{i}\right) x_{n} \rightarrow 0$, where $x_{n}=\left(x_{1}^{(n)}, x_{2}^{(n)}, \cdots\right) \in \ell_{2}$ and $z=\left(z_{1}, z_{2}, \cdots\right) \in \ell_{2}$. The weak convergence of $\left\{x_{n}\right\}$ to $z$ implies that $x_{j}^{(n)} \rightarrow z_{j}$ for each $j \geqslant 1$. Since

$$
\left\|\left(I-U_{i}\right) x_{n}\right\|^{2}=\sum_{k=1}^{i}\left|x_{k}^{(n)}\right|^{2}+\sum_{k=i+1}^{\infty}\left|x_{k-i}^{(n)}-x_{k}^{(n)}\right|^{2} \rightarrow 0,
$$

it follows that for each fixed $1 \leqslant k \leqslant i, x_{k}^{(n)} \rightarrow 0=z_{k}$. Hence

$$
z_{1}=z_{2}=\cdots=z_{i}=0 .
$$

Also, for $k \geqslant i+1, x_{k-i}^{(n)}-x_{k}^{(n)} \rightarrow 0=z_{k-i}-z_{k}$. Using (3.21) we see

$$
z_{\mathfrak{i}+1}=z_{\mathfrak{i}+2}=\cdots=z_{2 \mathfrak{i}}=0 .
$$

Using (3.22) again, we have $z_{2 i+1}=z_{2 i+2}=\cdots=z_{3 i}=0$. Continuing this process, we get all $z_{j}=0$ for all $j \geqslant 1$, which implies $z=(0,0, \cdots)=0 \in \operatorname{Fix}\left(U_{i}\right)$. Hence $I-U_{i}$ is demiclosed at 0 .

Furthermore, it is obvious that each $T_{i}$ is $\mu$-demicontactive, where $\mu=\frac{i}{i+2}$; see [9, Example 2.5]. However, for each $i \in\{1,2, \cdots p\}, I-T_{i}$ is obviously demiclosed at 0 by Remark 2.4 .

If $\mathrm{U}_{i}=\mathrm{U}, \mathrm{T}_{\mathrm{i}}=\mathrm{T}, \mathrm{i}=1,2, \cdots, \mathrm{p}$ in Theorem 3.2, we obtain the following conclusion.

Corollary 3.6. Let $\mathrm{U}$ be quasi-nonexpansive and $\mathrm{T}$ be $\mu$-demicontractive such that $\mathrm{I}-\mathrm{U}$ and $\mathrm{I}-\mathrm{T}$ are demiclosed at origin. Let $\mathrm{A}: \mathrm{H}_{1} \rightarrow \mathrm{H}_{2}$ be a bounded linear operator. Assume that $\Omega=\operatorname{Fix}(\mathrm{U}) \cap A^{-1}(\operatorname{Fix}(\mathrm{T})) \neq \emptyset$. Let $\rho$ be as in Lemma 2.7. For any $\mathrm{x}_{1} \in \mathrm{H}_{1}$, define the sequence $\left\{\mathrm{x}_{\mathrm{n}}\right\}$ by

$$
x_{n+1}=\left(1-\beta_{n}\right) x_{n}+\beta_{n} U\left[\left(1-\alpha_{n}\right)\left(x_{n}-\lambda_{n} A^{*}(I-T) A x_{n}\right)\right],
$$

where $\left\{\alpha_{n}\right\} \subset(0,1),\left\{\beta_{n}\right\} \subset[0,1],\left\{\lambda_{n}\right\} \subset[0,+\infty)$ satisfying the following conditions: 
(i) $0<\liminf _{n \rightarrow \infty} \beta_{n} \leqslant \limsup _{n \rightarrow \infty} \beta_{n}<1$;

(ii) $\lim _{n \rightarrow \infty} \alpha_{n}=0, \sum_{n=1}^{\infty} \alpha_{n}=\infty$;

(iii) $0<\liminf _{n \rightarrow \infty} \lambda_{n} \leqslant \limsup _{n \rightarrow \infty} \lambda_{n}<\frac{1-\mu}{\rho}$.

Then the sequence $\left\{x_{n}\right\}$ converges strongly to $\mathrm{P}_{\Gamma}(0)$, where $\Gamma$ is the solution set of the two-set SCFP (1.3).

If $U_{i}=U, T_{i}=T, i=1,2, \cdots, p$ in Theorem 3.4, we obtain the following conclusion.

Corollary 3.7. Let $\mathrm{U}$ be quasi-nonexpansive and $\mathrm{T}$ be $\mu$-demicontractive such that $\mathrm{I}-\mathrm{U}$ and $\mathrm{I}-\mathrm{T}$ are demiclosed at origin. Let $\mathrm{A}: \mathrm{H}_{1} \rightarrow \mathrm{H}_{2}$ be a bounded linear operator. Assume that $\Omega \neq \emptyset$ and $\rho$ is as in Lemma 2.7. For any $\mathrm{x}_{1} \in \mathrm{H}_{1}$, define the sequence $\left\{\mathrm{x}_{\mathrm{n}}\right\}$ by

$$
x_{n+1}=\left(1-\beta_{n}\right) W_{n} x_{n}+\beta_{n} u\left[\left(1-\alpha_{n}\right) W_{n} x_{n}\right],
$$

where $W_{n} x_{n}=x_{n}-\lambda_{n} A^{*}(I-T) A x_{n}$ and $\left\{\alpha_{n}\right\} \subset(0,1),\left\{\beta_{n}\right\} \subset[0,1],\left\{\lambda_{n}\right\} \subset[0,+\infty)$ satisfying the following conditions:

(i) $0<\liminf _{n \rightarrow \infty} \beta_{n} \leqslant \limsup _{n \rightarrow \infty} \beta_{n}<1$;

(ii) $\lim _{n \rightarrow \infty} \alpha_{n}=0, \sum_{n=1}^{\infty} \alpha_{n}=\infty$;

(iii) $0<\liminf _{n \rightarrow \infty} \lambda_{n} \leqslant \limsup _{n \rightarrow \infty} \lambda_{n}<\frac{1-\mu}{\rho}$.

Then the sequence $\left\{x_{n}\right\}$ converges strongly to $\mathrm{P}_{\Gamma}(0)$, where $\Gamma$ is the solution set of the two-set SCFP (1.3).

\section{Acknowledgment}

This research is supported by the Natural Science Foundation of China (no. 11401388, 11501431), the Natural Science Foundation of Zhejiang (no. LQ13A010007, LY14A010006).

\section{References}

[1] Y. Censor, T. Elfving, A multiprojection algorithm using Bregman projections in a product space, Numer. Algorithms, 8 (1994), 221-239. 1

[2] Y. Censor, A. Segal, The split common fixed point problem for directed operators, J. Convex Anal., 16 (2009), 587-600. 1, 1

[3] H.-H. Cui, M.-L. Su, F.-H. Wang, Damped projection method for split common fixed point problems, J. Inequal. Appl., 2013 (2013), 10 pages. 1, 1, 3.3

[4] K. Goebel, W. A. Kirk, Topics in metric fixed point theory, Cambridge Studies in Advanced Mathematics, Cambridge University Press, Cambridge, (1990). 2

[5] C.-C. Hong, Y.-Y. Huang, A strong convergence algorithm for the two-operator split common fixed point problem in Hilbert spaces, Abstr. Appl. Anal., 2014 (2014), 8 pages. 2.8

[6] P. E. Maingé, Strong convergence of projected subgradient methods for nonsmooth and nonstrictly convex minimization, Set-Valued Anal., 16 (2008), 899-912. 3, 3

[7] G. Marino, H.-K. Xu, Weak and strong convergence theorems for strict pseudo-contractions in Hilbert spaces, J. Math. Anal. Appl., 329 (2007), 336-346. 2.2, 2.9

[8] A. Moudafi, The split common fixed-point problem for demicontractive mappings, Inverse Problems, 26 (2010), 6 pages. $1,2.7$

[9] Y.-Q. Wang, T. H. Kim, Simultaneous iterative algorithm for the split equality fixed-point problem of demicontractive mappings, J. Nonlinear Sci. Appl., 10 (2017), 154-165. 2.3, 2.4, 3

[10] F.-H. Wang, H.-K. Xu, Cyclic algorithms for split feasibility problems in Hilbert spaces, Nonlinear Anal., 74 (2011), 4105-4111. 1, 2.6, 3

[11] H.-K. Xu, Iterative algorithms for nonlinear operators, J. London Math. Soc., 66 (2002), 240-256. 2.5

[12] Y.-H. Yao, R. P. Agarwal, M. Postolache, Y.-C. Liou, Algorithms with strong convergence for the split common solution of the feasibility problem and fixed point problem, Fixed Point Theory Appl., 2014 (2014), 14 pages. 1

[13] Y.-H. Yao, M. Postolache, Y.-C. Liou, Strong convergence of a self-adaptive method for the split feasibility problem, Fixed Point Theory Appl., 2013 (2013), 12 pages. 1

[14] Y.-H. Yao, J. Wu, Y.-C. Liou, Regularized methods for the split feasibility problem, Abstr. Appl. Anal., 2012 (2012), 13 pages. 1 